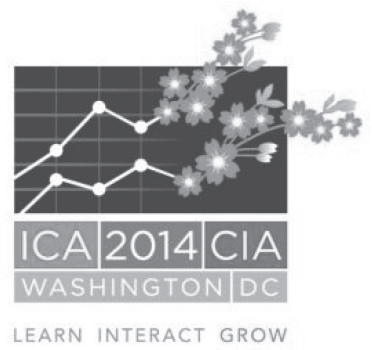

$30^{\text {th }}$ International Congress of Actuaries (ICA 2014) Scientific Committee Awards Prizes for Best Papers

Over 225 distinct papers and presentations were delivered in close to 100 parallel sessions throughout the five days of the Congress in these seven tracks: Life; Pensions, Employee Benefits Social Security; Professionalism and Education; Financial and Enterprise Risk; Consulting; Health; and Non-Life. The ICA 2014 Scientific Committee was pleased to recognize sixteen of these papers with prizes of USD $\$ 1,000$ prize each. The Committee also thanks IAA's AFIR/ERM and PBSS sections for their contributions toward prizes in the Finance and Enterprise Risk and Pensions, Benefits, Social Security tracks respectively.

The winners are:

Life

- Marcus Christiansen and Andreas Niemeyer, "Forward Transition Rates in Multi-state Models"

- Matthias Fahrenwaldt, "Sensitivity of Life Insurance Reserves via Markov Semigroups"

\title{
Pensions, Benefits Social Security
}

- Kudzai Chigiji, Johann Songhe, Krishen Sukdev, Natalie van Zyl, Fatima Badat; “The Evolution and Future of Social Security in Africa: An Actuarial Perspective"

- Matthias Boerger, "Coherent Projections of Age, Period, and Cohort Dependent Mortality Improvements"

- Bonnie-Jeanne MacDonald, "How Accurately does 70\% Final Earnings Replacement Measure Retirement Income (In)Adequacy?"

\section{Professionalism and Education}

- Robert Brown, "The Power of the Collective; The Death of the Collective"

- Eduardo Melinsky, "Perspectives of Social Security in Latin America and the Role of The Actuary"

Financial and Enterprise Risk

- Towers Watson's Thinking Ahead Group (TAG), "Risk Appetite Revisited"

- Darja Stepchenko, "Operational Risk Effect on Insurance Market's Activity"

\section{Consulting}

- Robin Penfold, "Evaluating an Investment Manager in an Uncertain World"

- Liaw Huang of The Terry Group, "Communicating Longevity"

Health

- Lee Sarkin and Rory Leisegang, "Insurability and Survival of Lives Living with HIV and Other Chronic Disease"

- Shivani Ramjee, "An Actuarial Perspective on Healthcare Expenditure in the Last Year of Life"

\section{Non-Life}

- (1st) Daniel Bauer and George Zanjani, "The Marginal Cost of Risk in a Multi-Period Risk Model"

- (2nd) Mona Salah Ahmed Hammad, "A Primer in Multilevel Modeling for Actuarial Applications" 


\section{LIFE, IACA AND PBSS COLLOQUIUM}

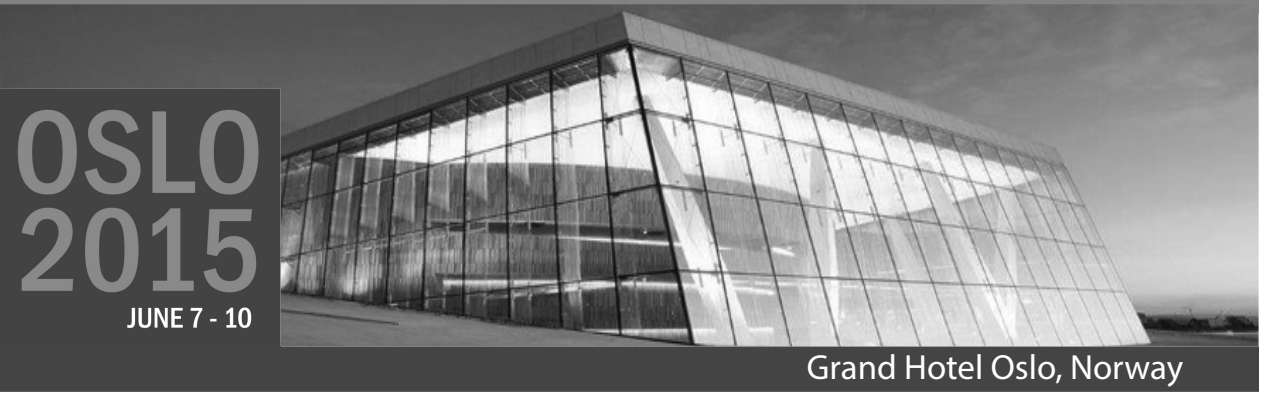

Den norsk Aktuarforening invites you to attend the Colloquium of the International Actuarial Association to be held in Oslo, Norway, from the 7th to the 10th of June 2015. The colloquium is a joint collaboration of three IAA sections: Pension Benefits and Social Security (PBSS), Life Insurance (LIFE) and Consulting Actuaries (IACA).

Our call for papers describes the present state of pensions and life insurance as rather turbulent and lists a number of issues that serve to shape the prospectus of the colloquium. Hopefully it will inspire many of you to write a contributed paper and many more of you to attend and participate in the discussions in Oslo. Enjoy the bright summer nights in the little city with the big heart!

\section{Call for Papers 'Issues in our time'}

A relatively short period in the history of insurance, the past some three decades have seen life insurance and pensions undergo major changes driven by multiple and interacting forces. The following list of keywords is probably noncontroversial, but emphasis and pros and cons may be debatable. Deregulation in the eighties. Financial innovation and emergence of huge derivatives markets. Growth in volume of trades, increasingly research- and technology-driven. Financial instability culminating in the on-going crisis. In life insurance and pensions: Demutualization, dissolution of portfolios, increasing mobility of insurance contracts (buy-outs, individual and bulk), surrenders and free policies. The traditional with profit scheme gave way to a plethora of products equipped with various forms of guarantees. Hence risk management increasingly based on market operations: reinsurance, swaps, securitization. Pension crisis triggered by faltering markets and improved longevity. Occupational schemes moving from defined benefits to defined contributions. Renewed interest in with profit? Or seek new ways of adapting premiums and benefits to indices for interest and mortality? Risk classification driven by technology (gene tests) or legislation (gender neutrality). Disability and long term care in an ageing population. Reintroduction of regulation. Solvency II, IFRS, external models vs internal models/ORSA. Valuation of assets and liabilities (what is MCEV?). Furthemore: consolidation, globalization, emergence of insurance markets in developing countries. And, not least, the impact of advances in the mathematical theories of finance and insurance and their interface.

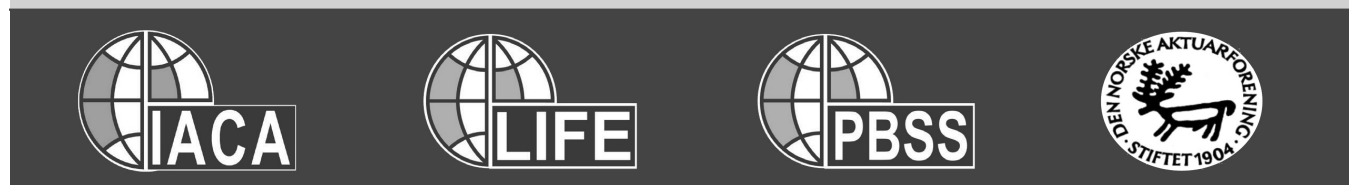




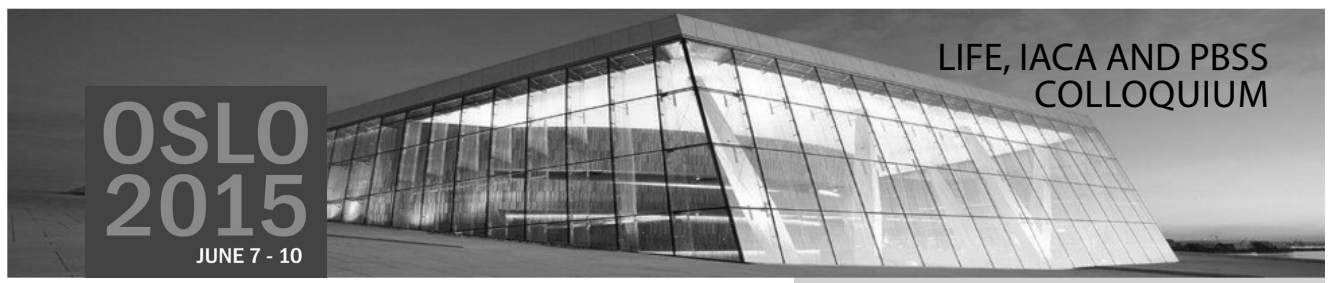

\section{About Oslo}

Important Information

"The Blue the Green and the Capital in between"

Oslo is situated at the head of Oslo Fjord surrounded by forested ridges, and this very location gives the city unexpected qualities for a national capital. The surrounding countryside provides recreational opportunities for the city's inhabitants and visitors, in summer as well as in winter. Not many world capitals offer subway service to the forest, with lakes and hiking trails within city limits.

Oslo has a population of only 600000 , which is relatively low compared to most European capitals. However, it is paradoxically one of the largest in terms of area. Oslo covers more than 450 square kilometers, most of which comprises forests and arable land.

Oslo is a city full of contrasts. Its natural beauty, in combination with all the facilities of a modern metropolis, adds to the charm of a city often called "the world's biggest village".

More modern districts include the bustling Aker Brygge area, a rehabilitated old shipyard, with its Mediterranean style shops, restaurants and cafés. Oslo's beautiful natural surroundings, its varied architecture, and its multinational inhabitants contribute to the city's unique atmosphere.

And Oslo's climate is actually better than our northern latitude might indicate. This is due to the Gulf Stream bringing warmth from the Gulf of Mexico across the Atlantic Ocean and along the coast of Norway. And in the summer, the sun is up 19 hours per day.
Best Paper Awards

The LIFE and PBSS Sections are granting two prizes of CAD 1000 each, one to the author(s) of the best IAALS paper and one to the author(s) of the best PBSS paper. The winners will be selected by the Scientific Committee and be announced and awarded their prizes during the Colloquium.

\section{Call for Papers}

Synopsis Deadline: 31 January, 2015

Draft Program Released: 28 February, 2015

Paper and Peer Review Form Submission Deadline: 31 March, 2015

Acceptance Deadline: 15 April 2015

Presentation File Deadline: 31 May 2015

Registration to Open: Autumn 2014

\section{Keynote Speakers}

- Professor An Chen, University of Ulm, Germany

- Managing director Idar Kreutzer, Finance Norway, Norway

- Professor Antoon Pelsser, University of Maastricht, The Netherlands

- Professor Mogens Steffensen, University of Copenhagen, Denmark
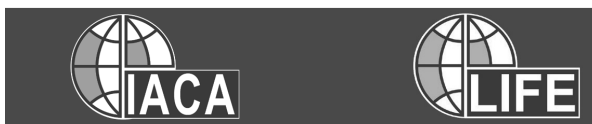

\section{Contact Information}

For more information about submissions or papers please contact oslo2015@ccnorway.no or visit www.actuaries.org/oslo2015 


\section{ASTIN and $A=R / E R M$ Colloquium}

Innovation \& Invention

23-27 August 2015 | Amora Hotel Jamison Sydney

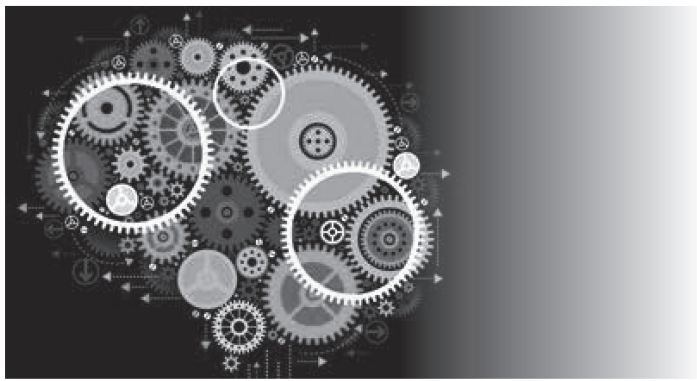

\section{Call for Papers}

7

he Actuaries Institute invites you to attend the Colloquium of the Internationa Actuarial Association to be held in Sydney, Australia, from 23 to 27 August 2015

This colloquium is a joint collaboration of two IAA sections, the Actuarial Approach for Financial Risks/Enterprise Risk Management (AFIR/ERM) and Actuarial Studies in Non-Life Insurance (ASTIN).

Further details of the Colloquium can be found at www.actuaries.org/sydney2015/

\section{Innovation and Invention}

Australia has a long and proud history of innovation and invention in many scientific and practical disciplines. Here are some examples:

Whilst Fleming discovered the antibacterial properties of penicillin in his London laboratory, it was a team led by the Australian researcher Howard Florey that purified the strain and demonstrated its efficacy in humans. Australia was the first country to mass-produce the wonder drug for non-military use.

- In 1961, chemist Dave Warren joined an Australian team investigating a series of plane crashes. He came up with the idea of the black box flight recorder and developed a prototype in Australia. Today every commercial plane carries a flight recorder.

- In 1836 the HMS Beagle began its survey of Australia, carrying the young naturalist Charles Darwin on board. Darwin's specimen collections and observations from Australia and around the world provided strong evidence for his theory of evolution published in 1860

- Robert Brown the Botanist who gave Brownian motion its name spent several years in Australia discovering new plant species.

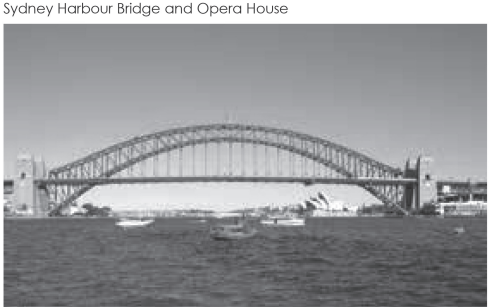

\section{Sydney and Australia}

The site of the first European settlement in Australia, Sydney

has something to offer any visitor, including:

- Visit the Sydney Opera House;

- Climb to the top of the Sydney Harbour Bridge.

- Explore the shops, pubs and restaurants of The Rocks or Darling Harbour.

- Take a ferry trip to the

- Visit the Museum of Contemporary Art Australia, the Australian Museum or the Art Gallery of New South Wales.

- Just relax and learn to surf at Bondi Beach.

The Blue Mountains, a World Heritage area, and the Hunter Valley wine region are only a day trip from Sydney. Further afield are the natura wonders of the Great Barrier Reef, the Great Ocean Road, Uluru, and the Kakadu National Park. The Colloquium is the perfect excuse for an extended trip to see Australial

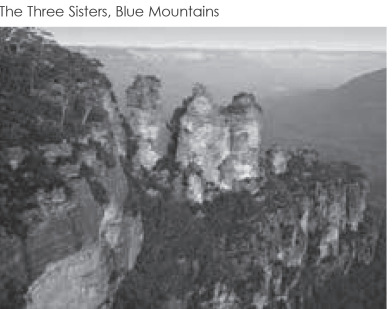
Taronga Zoo or Manly.

\section{Actuaries}

\section{Call for Papers}

Synopsis Deadline:

27 February 2015

Draft Program Released: 27 March 2015

Paper Submission Deadline:

15 April 2015

Acceptance Deadline:

15 May 2015

Published on Website: 29 May 2015

Registration to open in February 2015

\section{Submissions}

ASTIN and AFIR/ERM final papers should be sent to:

events@actuaries.asn.au by 15 April 2015 .

\section{Contacts}

For more information about submissions or papers please contact:

ASTIN:

Greg Taylor

greg_taylor60@hotmail.com

AFIR/ERM:

Michael Sherris

m.sherris@unsw.edu.au

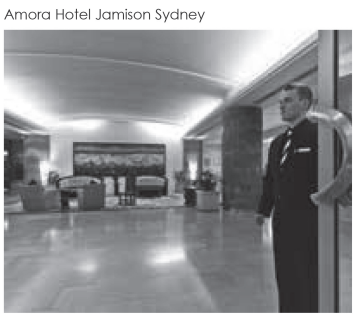




\section{ASTIN and AFIR/ERM Colloquium}

Innovation \& Invention

23-27 August 2015 | Amora Hotel Jamison Sydney

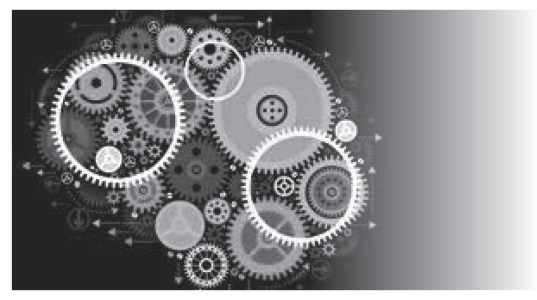

\section{Actuaries} Institute

\section{Topics for AFIR/ERM}

The ASTIN Scientific Committee seeks papers on the following topics:

- Loss reserving and capital adequacy

- Insurance pricing and price optimisation

- Predictive modelling and business analytics

Reinsurance and risk transfer

- Risk management

- Natural hazards and disaster pricing

- Capital management, allocation and pricing

- Longevity, health and employment insurance

Risk theory

- Dividend theory and practice

- Copulas: theory and applications

\section{Topics for AFIR/ERM}

The AFIR/ERM Scientific Committee seeks papers in the areas of finance, financial economics, and the management of financial risks, focusing on applications to insurance and pension funds. Specific topics of interest are:

- Investment and asset allocation

- Portfolio risk management

- Bond portfolio management

- Asset/Liability Management (ALM)

- Enterprise risk management (ERM)

- Risk measures and capital allocation

- Managing retirement accumulations and decumulations

- Dynamic asset allocation

- Asset and derivative pricing

- Longevity, health and mortality risk

- Pricing and risk management for product guarantees

- Solvency and risk based capital
Guidelines for papers for both ASTIN and AFIR/ERM

1. Synopsis submissions need to be submitted in the required Synopsis Template and submitted to events@actuaries.asn.au by 27 February 2015.

2. Completed papers need to submitted to events@actuaries.asn.au by the 15 April 2015. Paper extensions will not be granted.

3. All papers need to be submitted with a paper Coversheet. The main text should start on page 2. Pages must be numbered. References must be organized alphabetically, multiple references for a single author must be ordered chronologically. Journal references must include author, year, title, journal title, volume and pages. Book references must include author, year, title, editor and city. For more details, refer to the Paper Guidelines.

4. Papers should be written in English and must be received by the closing date. All papers must be submitted electronically in PDF format.

5. If you do not receive an email acknowledging receipt of your paper by $\mathbf{1 5}$ May, 2015 please contact events@actuaries.asn.au

6. Submitted papers will be evaluated by the Scientific Committees, and acceptance of the papers will be confirmed no later than the acceptance date.

7. A list of accepted papers, and the final accepted papers will be posted on the website.

Hunter Valley, NSW - wine region

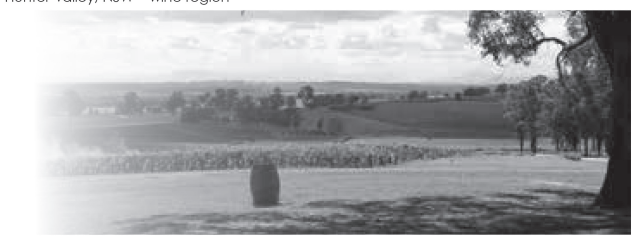

Sydney's iconic Bondi Beach

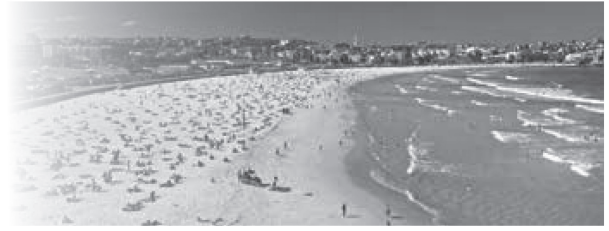

Great Barrier Reef, Queensiand

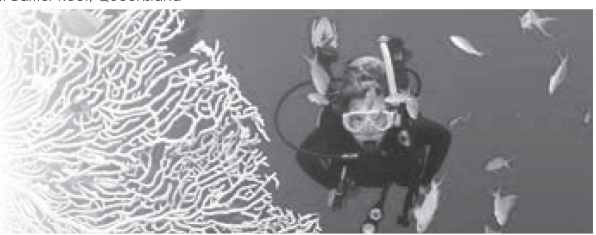




\section{ASTIN Bulletin: The Journal of the International Actuarial Association NOTES FOR CONTRIBUTORS}

\section{AIMS AND SCOPE}

ASTIN Bulletin was founded in 1958 as a journal providing an outlet for actuarial studies in non-life insurance. In the late 1980's the journal extended its scope to encompass the study of financial risk in insurance (AFIR). In 2007 the journal was established as the journal of the International Actuarial Association (IAA) and encompasses all of the scientific sections of the IAA.

ASTIN Bulletin publishes papers that are relevant to any branch of actuarial science and insurance mathematics. Papers should be quantitative and scientific in nature, and might draw on theory and methods developed in any branch of the mathematical sciences including actuarial mathematics, statistics, probability, financial mathematics and econometrics.

The journal welcomes papers that present significant and original theoretical developments and papers that present significant and original applications of mathematical, statistical or econometric theory to problems arising in insurance, pensions and finance. We especially welcome papers opening up new areas of interest to the international actuarial profession as well as papers that describe open problems that have arisen in practice.

\section{SUBMISSIONS}

Papers for possible publication in the ASTIN Bulletin - The Journal of the International Actuarial Association should be submitted online at: http://mc.manuscriptcentral.com/astin. Submission of a paper is held to imply that it contains original unpublished work and is not being submitted for publication elsewhere. Receipt of the paper will be confirmed and followed by a refereeing process which will be handled by one of the editors. The editors aim to complete the refereeing of a submission in around three months. The role of a referee is to assess the quality of the academic content of the paper. If a paper is sufficiently badly written to an extent that prevents a referee from forming a proper view of the paper's scientific content, then the paper will be returned to the author unrefereed.

\section{TEXT AND MANUSCRIPT PREPARATION REFERENCING}

Before a manuscript can be published it must conform to the style of ASTIN Bulletin, a summary of the key points of which is listed below. The comprehensive Notes of Contributors document can be obtained from http://journals.cambridge.org/asb/contributors.

- The basic elements of the journal's style have been agreed by the Editors and the publisher and should be clear from checking a recent issue of ASTIN Bulletin. If variations are felt necessary, this should be discussed with the editor handling the paper.

- Papers should be written in English or French. It is not the job of the editors, the referees or the publisher to improve the use of English or French in the paper; it is up to the authors to ensure that the language, spelling and grammar are of a high quality prior to submission.

- Authors intending to submit longer papers (e.g. exceeding 30 pages) are advised to consider splitting their contribution into two or more shorter contributions.

- The first page of each paper should start with the title, the name(s) of the author(s), an abstract and a list of keywords. An institutional affiliation can be placed between the name(s) of the author(s) and the abstract.

- Footnotes should be avoided as far as possible.

\section{AUTHOR AND CONTACT INFORMATION}

On the title page, please provide the full name, affiliation, email and postal address of at least one author. Where the family name may be ambiguous (e.g. a double name), please indicate this clearly. For joint authored papers, please indicate the lead corresponding author and provide a contact telephone number.

\section{REFERENCING}

References should be arranged alphabetically, and for the same author chronologically. Use a, b, c etc. to separate publications of the same author in the same year. For journal references give author(s), year, title, journal (in italics), volume (in boldface), and pages. For book references give author(s), year, title (in italics), publisher, and city. 


\section{ASTIN Bulletin}

Volume 44

Issue 3

\section{CONTENTS}

\section{Industry Discussion Article}

An industry question: The ultimate and one-year reserving uncertainty for different non-life reserving methodologies

ERIC Dal Moro AND Joseph Lo

\section{Articles}

Fundamental definition of the Solvency Capital Requirement in Solvency II Marcus C. Christiansen and Andreas Niemeyer

Annuitization behavior: tax incentives vs. product design

Alexander Kling, Andreas Richter and Jochen Ruß

State-dependent fees for variable annuity guarantees

Carole Bernard, Mary Hardy and Anne Mackay

A posteriori ratemaking with panel data

JeAn-Philippe Boucher AND Rofick INOUSSA

On some properties of two vector-valued VaR and CTE multivariate risk measures for Archimedean copulas

WERNER HÜRLIMANN

On the optimal dividend problem for a spectrally positive Lévy process

Chuancun Yin, Yuzhen Wen and YongXia Zhao

Spectral methods for the calculation of risk measures for variable annuity guaranteed benefits

Runhuan Feng and Hans W. Volkmer 